\title{
Studies of condensation/evaporation processes in the Glowworm Cave, New Zealand
}

\author{
C.R. de Freitas ${ }^{1}$ and A. Schmekal ${ }^{2}$
}

\begin{abstract}
:
de Freitas C.R. and Schmekal A. 2006. Studies of condensation/evaporation processes in the Glowworm Cave, New Zealand.. International Journal of Speleology, 35 (2), 75-81. Bologna (Italy). ISSN 0392-6672.

The condensation/evaporation process is important in caves, especially in tourist caves where there is carbon dioxide enriched air caused by visitors. The cycle of condensation and evaporation of condensate is believed to enhance condensation corrosion. The problem is condensation is difficult to measure. This study addresses the problem and reports on a method for measuring and modelling condensation rates in a limestone cave. Electronic sensors for measuring condensation and evaporation of the condensate as part of a single continuous process of water vapour flux are tested and used to collect 12 months of data. The study site is the Glowworm tourist cave in New Zealand. The work describes an explanatory model of processes leading to condensation using data based on measurements of condensation and evaporation as part of a single continuous process of water vapour flux. The results show that the model works well. However, one of the most important messages from the research reported here is the introduction of the condensation sensor. The results show that condensation in caves can actually be measured and monitored, virtually in real time. In conjunction with the recent developments in data logging equipment, this opens exciting perspectives in cave climate studies, and, more generally, in hydrogeological studies in karst terrains.
\end{abstract}

Keywords: condensation, cave microclimate, evaporation, management of show caves

Received 30 March 2006; Revised 28 April 2006; Accepted 26 May 2006

\section{INTRODUCTION}

The condensation/evaporation process to and from cave rock plays a variety of roles in speleogenesis, but two of these are particularly important. The first occurs where water condensing onto cave walls that are made of a soluble rock mineral (calcite, dolomite, gypsum, halite, carnallite etc.) is undersaturated with respect to the mineral, the potential exists for dissolution to occur. This process called condensation corrosion may create surface impressions on speleogen features. Water from condensation can cause this because its chemistry makes it aggressive. Carbon dioxide, water and calcium carbonate (limestone or calcite) react to give soluble calcium and hydrogencarbonate ions in water. Condensation water becomes considerably more corrosive if it contains substantial amounts of dissolved carbon dioxide. In tourist or show caves, for example, visitors breathe out warm air saturated with water vapour together with over $4 \%$ by volume of

1) School of Geography and Environmental Science, The University of Auckland, New Zealand

Email: c.defreitas@auckland.ac.nz

2) School of Geography and Environmental Science, The University of Auckland, New Zealand carbon dioxide at a temperature usually much higher than the cave air. The moisture in this air containing high concentrations of carbon dioxide might condense as it comes into contact with the colder cave air and walls. The second process occurs during times when condensation water evaporates and carbon dioxide is removed from saturated solutions of calcium and hydrogencarbonate ions causes precipitation of calcite. This process produces soft unattractive microcrystalline, flaky deposits of calcite. This cycle of condensation and evaporation of condensate is believed to enhance condensation corrosion (TarhuleLips \& Ford, 1998).

Increasing cave tourism worldwide presents problems because of this irreversible degradation. Previous work on tourist caves, has shown that an understanding of cave microclimate processes is crucial to understanding, managing and protecting the cave ecosystem (de Freitas, 1998; de Freitas \& Banbury, 1999), but gaps in understanding certain key processes remain, in particular, those governing condensation. Condensation in caves has been addressed in the research literature, such as by Cigna \& Forti (1986) and recently by Badino (2004) and Dreybrodt et al. (2005), but there are still large gaps 
in the understanding of the moisture flux process. Papers by Dublyansky \& Dublyansky (1998, 2000) that review the topic confirm this. Explanatory models of causal process are speculative and remain untested. A large part of the problem is difficulties in measuring condensation in order to study it. Recently, however, de Freitas \& Schmekal (2003) devised a reliable method for measuring condensation and evaporation as part of a single continuous process of water vapour flux. The aim here is to report on this research to cave scientists, specifically on the method for measuring condensation rates on cave rock surfaces.

\section{STUDY SITE}

The study site is the Glowworm Cave, New Zealand, widely regarded as an attraction of considerable aesthetic and ecological significance. It has one of the highest visitor usage rates of any conservation land in New Zealand. Four times the number of people visit the Glowworm Cave than the next most popular cave in either New Zealand or Australia. For this reason it is considered to be a valuable national resource and one that requires careful management if its attractiveness is to be protected and the resource sustained.

The Glowworm Cave is located in the North Island of New Zealand at latitude $38^{\circ} 15^{\prime}$ 'S, longitude $175^{\circ} 06^{\prime} \mathrm{E}$. The region has a sub-temperate climate with an average annual rainfall of $1530 \mathrm{~mm}$. Average daily maximum and minimum air temperatures in the warmest month, January, are 24.1 and $12.6{ }^{\circ} \mathrm{C}$, respectively. Average maximum and minimum temperatures in the coolest month, July, are 13.1 and $3.3{ }^{\circ} \mathrm{C}$, respectively. The water vapour content of the air is relatively high throughout the year in the region, with a mean vapour pressure of $13 \mathrm{hPa}$. The cave is situated in a ridge of Oligocene limestone. The area above the cave is a scenic reserve of native vegetation administrated by the New Zealand government agency called the Department of Conservation.

The Glowworm Cave is made up of $1,300 \mathrm{~m}$ of interconnected passageways with an estimated volume of approximately $4000 \mathrm{~m}^{3}$. The cave has two entrances, an upper entrance and a lower entrance, $14 \mathrm{~m}$ vertically apart. The upper entrance is equipped with a solid door that, when closed, seals the opening preventing airflow. The upper entrance leads into two passages, one $40 \mathrm{~m}$ long leading to the Blanket Chamber and the other the Main Passage $39 \mathrm{~m}$ long (Fig. 1). The latter passage leads past the Tomo shaft which connects to the lower level Glowworm Grotto. The Blanket Chamber opens out into the Cathedral, which is a $40 \mathrm{~m}$ long and $13 \mathrm{~m}$ high chamber, the largest in the cave (Fig. 1). The Organ Loft Side Passage, which leads from the Cathedral area to the Organ Loft chamber, is a cul-de-sac passage. The lowest part of the cave is the Glowworm Grotto which is part of the stream passage of the Waitomo River. The Glowworm Grotto is a large chamber approximately $30 \mathrm{~m}$ long and $10 \mathrm{~m}$ wide and has the main displays of the glowworm (Arachnocampa luminosa) in the cave. From here the stream flows down through a passage and sump and then past the Demonstration Chamber. After this the stream flows for approximately another $180 \mathrm{~m}$ before leaving the cave (Fig. 1).

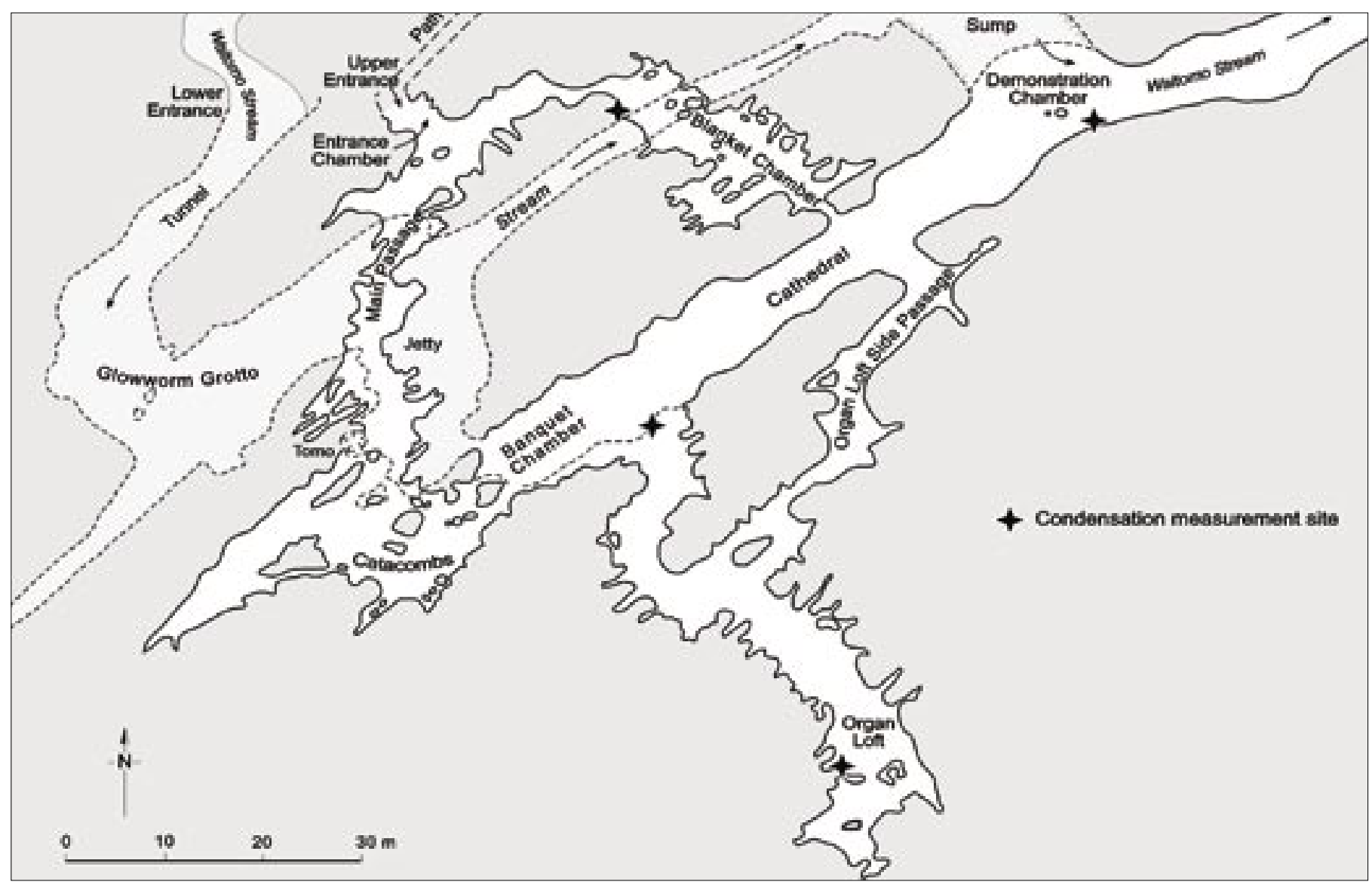

Fig. 1. Map of the Glowworm Cave, Waitomo, New Zealand showing condensation measurement sites and named cave features. The cave outline is based on surveys by L.O. Kermode (New Zealand Geological Survey, DSIR, 1974) and others 
Airflow in the cave has been studied in detail by de Freitas et al. (1982) and shown to be the key component of a cave's climate (de Freitas \& Littlejohn, 1987). The speed and direction of flow is determined by the difference of mean density of the outside and inside air (de Freitas et al., 1982). Since air density is mainly a function of air temperature, the latter can be used as the main indicator of airflow (de Freitas et al., 1982). When the outside air is cooler and thus denser than the cave air, the warmer cave air rises and flows towards and then through the Upper Entrance and replaced by cold air at the Lower Entrance. When cave air is cooler and denser than the air outside the cave, it flows down through the cave and out the Lower Entrance (de Freitas et al., 1982). In transitional times where the temperature gradient inside and outside the cave is small, there is little or no airflow.

\section{MODELLING CONDENSATION}

Condensation is part of a dynamic process of moisture flux that in addition involves evaporation. The process may be thought of as a continuous cycle of condensation and evaporation of condensate, shown conceptually in Fig. 2. When the amount of condensation over a given period exceeds the evaporation of condensate over that same period, condensation is observed to have occurred. Condensation water will accumulate if this condition prevails, otherwise it will evaporate (Fig. 2). The assumption is that at the surface there is a boundary layer of air that is saturated and has the same temperature as the surface. This boundary layer interacts with the surrounding air causing condensation or evaporation of condensate in a dynamic relationship that is driven in large part by the vapour gradient. The moisture flux across this gradient - strictly speaking the resistance to the diffusion of vapour across the boundary layer - is controlled by the rate of air movement and the roughness of the surface
(Monteith, 1957), collectively referred to here as the combined convection moisture transfer coefficient. Condensation occurs when the dewpoint temperature of the cave air is higher than the temperature of the rock surface. However, to quantify the movement of a mass of water vapour, specific humidity rather than dewpoint temperature must be used. The rate of condensation $(\mathrm{C})$ is given as:

$$
\mathrm{C}=\left(\mathrm{q}_{\mathrm{r}}-\mathrm{q}_{\mathrm{a}}\right) \mathrm{k}_{\mathrm{v}}
$$

where $\mathrm{C}$ is rate of condensation $\left(\mathrm{g} \mathrm{m}^{-2} \mathrm{~s}^{-1}\right), \mathrm{q}_{\mathrm{a}}$ is specific humidity of the air $\left(\mathrm{g} \mathrm{kg}^{-1}\right), \mathrm{q}_{\mathrm{r}}$ is saturation specific humidity at surface temperature $\left(\mathrm{g} \mathrm{kg}^{-1}\right), \mathrm{k}_{\mathrm{v}}$ is the combined convective water vapour transfer coefficient $\left(\mathrm{g} \mathrm{m}^{-2} \mathrm{~s}^{-1}\right)$. Specific humidity terms $\mathrm{q}_{\mathrm{a}}$ and $\mathrm{q}_{\mathrm{r}}$ are a function of vapour pressure and can be calculated from Neiburger et al. (1982):

$$
\begin{aligned}
& \mathrm{q}_{\mathrm{r}}=0.622 \frac{\mathrm{e}_{\mathrm{sr}}}{\mathrm{e}_{\mathrm{atm}}-\mathrm{e}_{\mathrm{sr}}} \\
& \mathrm{q}_{\mathrm{a}}=0.622 \frac{\mathrm{e}}{\mathrm{e}_{\mathrm{atm}}-\mathrm{e}}
\end{aligned}
$$

where $\mathrm{e}_{\mathrm{sr}}$ is saturation vapour $(\mathrm{hPa})$ pressure at rocksurface temperature and $\mathrm{e}$ is vapour pressure of the ambient air $(\mathrm{hPa})$ and $\mathrm{e}_{\mathrm{atm}}$ vapour pressure of external air $(\mathrm{hPa})$. Where vapour gradients are very small, as is frequently the case in cave environments, more precise formulae are required for the calculation of vapour pressure and saturation vapour pressure. Jensen (1983) has provided a highly accurate procedure complete with computer program that does this.

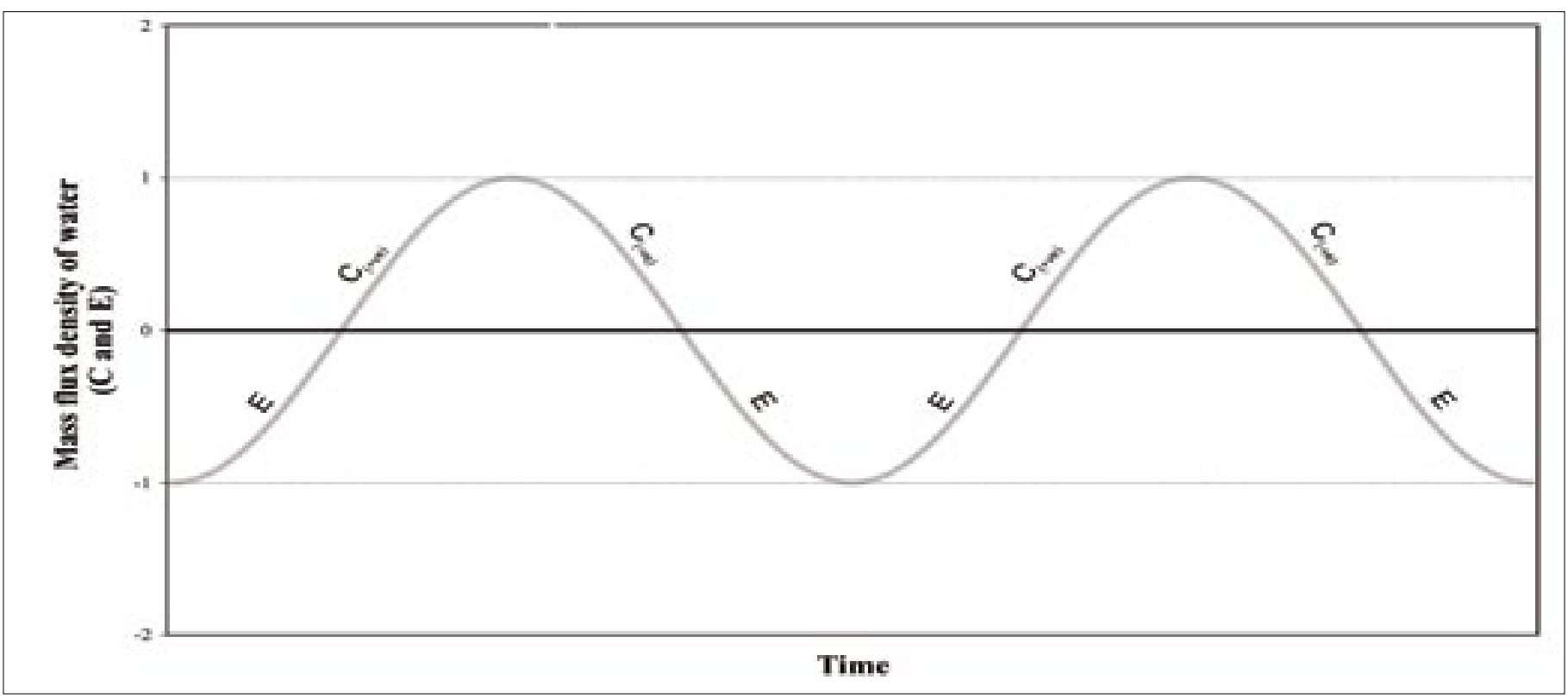

Figure 2. Conceptual model of the continuous, dynamic process of vapour flux to or from a surface as condensation and evaporation respectively. Condensation $(C)$ occurs when $C$ is positive $\left(C_{+v e}\right)$ and evaporation of condensate occurs when $C$ is negative $\left(C_{-v e}\right)$. Over a period of time $C_{(+v e)}$ and $\mathrm{C}_{(-\mathrm{ve})}$ yield a net moisture flux $(\mathrm{C})$. When condensate is present, $\mathrm{C}_{(-\mathrm{ve})}$ is determined by the evaporative capacity of the air. When all the condensate has evaporated, $\mathrm{C}_{(-\mathrm{ve})}$ and $\mathrm{C}$ will be zero. 
The combined convective water vapour transfer coefficient, $\mathrm{k}_{\mathrm{v}}$, is a function of air movement and surface roughness. It varies as the thickness of the boundary layer varies, mainly due to the velocity of air shearing the boundary layer and reducing its thickness. In its simplest form it is expressed as:

$$
\mathrm{k}_{\mathrm{v}}=\mathrm{h}_{\mathrm{v}} / \lambda
$$

where $h_{v}$ is the secondary convective transfer coefficient $\left(\mathrm{W} \mathrm{m} \mathrm{m}^{-2}\right)$ and $\lambda\left(\mathrm{J} \mathrm{g} \mathrm{g}^{-1}\right)$ is the latent heat of condensation (or vaporisation) at air temperature $\left(T_{d b}\right)$. The formula for $h_{v}$ for a flat surface is given by Pedro \& Gillespie (1982) as:

$$
\mathrm{h}_{\mathrm{v}}=1.07\left(\lambda / \mathrm{c}_{\mathrm{a}}\right) \mathrm{h}_{\mathrm{c}}
$$

where $\mathrm{c}_{\mathrm{a}}$ is the specific heat of air $\left(\mathrm{J} \mathrm{kg}^{-1} \mathrm{~K}^{-1}\right)$ and $h_{c}$ is the primary convection coefficient. According to McAdams (1954) $h_{c}$ is:

$$
\mathrm{h}_{\mathrm{c}}=5.9+4.1 \mathrm{v}\left(511+294 / 511+\mathrm{T}_{\mathrm{db}}\right)
$$

where $\mathrm{v}$ is wind speed $\left(\mathrm{m} \mathrm{s}^{-1}\right)$.

\section{MEASURING CONDENSATION}

There is no standard method for measuring condensation, although there are instruments available for measuring dew accumulation and dew duration. Rosenberg (1969), Richards (2002) and Richards \& Oke (2002) used mini-lysimeters for measuring dew on bare soil and grass respectively, but this is not suited to measuring condensation on cave rock. Surface wetness is often measured in microclimate studies of crops to determine the presence or absence of moisture on leaves, or dew duration (Davis \& Hughes, 1970; Gillespie \& Kidd, 1978; Häckell, 1980). The drawback is that this method does not measure the flux of moisture. By overcoming this, the approach was adapted for use in a cave environment by de Freitas \& Schmekal (2003) who devised a novel method for measuring this exchange of moisture to and from a surface using what they called "condensation sensors". They are simple to construct and their size can be customised so it is possible to install them on uneven surfaces such as a cave wall. The condensation sensors consist of an electrical grid of two sets of parallel wires mounted on a circuit board. When condensation occurs or evaporation of the condensate takes place on the sensor's surface, the resistance between the wires changes. To provide greater sensitivity, the wiring consisted of multiple fingers of interleaved conductive tracks made of copper (Fig. 3). Sensitivity can be altered by varying the number of conductors.

To obtain rates of condensation, conduction readings have to be converted to equivalent vapour fluxes. To do this the sensor are weighed when dry and the conductivity reading set at zero. Using an atomiser, very fine drops of water were sprayed onto the sensor in stages and weighed at each step (de Freitas \& Schmekal, 2003). The sensors showed no influence of ambient temperature over the range tested $\left(10\right.$ to $\left.20^{\circ} \mathrm{C}\right)$.

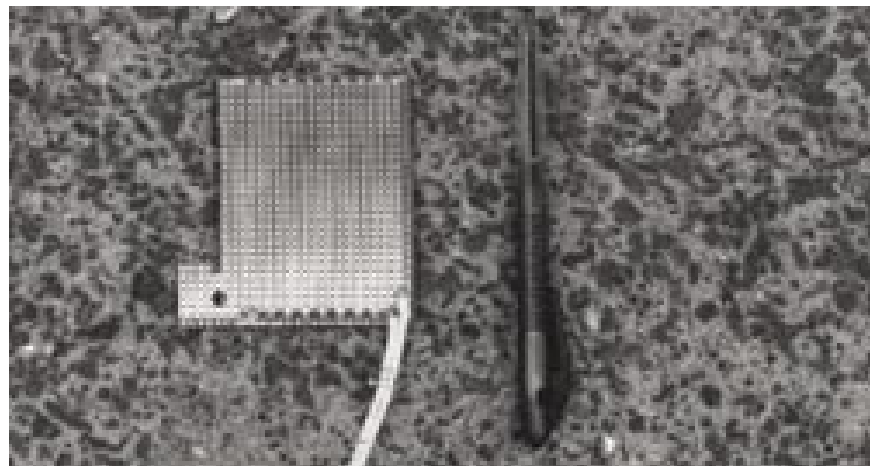

Fig. 3. Condensation sensor, consisting of an electrical grid of two sets of parallel wires mounted on a circuit board. When condensation occurs or evaporation of the condensate takes place on the sensor's surface, the resistance between the wires changes. To provide greater sensitivity, the wiring consists of multiple fingers of interleaved conductive tracks made of copper. Tinning the copper tracks prevents corrosion.

\section{DATA COLLECTION}

Data were assembled using a fully automated system of sensors and recorders and supplemented by direct measurement using hand-held instruments. Automated measurements were made of wet $\left(\mathrm{T}_{\mathrm{wb}}\right)$ and dry bulb $\left(\mathrm{T}_{\mathrm{db}}\right)$ air temperature, rock temperature $\left(\mathrm{T}_{\mathrm{r}}\right)$, and airflow rate and direction. Wet and dry bulb temperatures (Campbell 107B thermistors) were measured at the Tomo, Banquet Chamber and at the Jetty (Figure 1). Another dry bulb thermistor and humidity sensor (Vaisala Hummitter 50Y) was installed outside the cave. Readings were recorded by data loggers (Campbell CR10). Rate of airflow and direction into and out of the cave are measured using a sensitive Pulse Output Anemometer (A101M) and an airflow direction sensor (Potentiometer Wind vane W200P). The airflow instruments were located in the entrance area, just inside the cave door. An electronic sensor records periods when the entrance-door is open and airflow readings are taken every three seconds. The data logger then records the maximum wind speed for each one-minute interval, and these are then averaged for the length of the time the entrance-door is open. Rock temperature was measured using a thermistor (Campbell 107B). Internal rock temperatures give an indication of trends in the longer-term thermal state of the cave, as well as the direction of heat flow to and from the rock-surface (de Freitas, 1998). Rock temperatures were measured at the Tomo recorded every six hours.

To sample more extensively through the cave, direct measurements were made using hand held instruments. Wet bulb temperature and dry bulb temperature were measured using a full-sized Assmann Psychrometer (Casella, Type 8900/1). The instrument can be read with accuracy to a resolution of $0.1^{\circ} \mathrm{C}$. From these data, saturation vapour pressure, humidity and dew-point temperature were determined using the procedure described earlier. For detailed measurements of airflow in various parts of the cave, a Dwyer hot-wire anemometer (Series 470), accurate to $0.05 \mathrm{~m} \mathrm{~s}^{-1}$, was used. Rock-surface temperatures were measured using a portable electronic instrument 
(Ultrakust, Type 4444-1B) and probe especially designed for measuring surface temperature of flat, solid objects. The flat temperature-sensing element of the probe is covered with an insulating epoxy and fibreglass resin attached to Teflon insulated leads to protect it from the thermal influences of air when it is pressed against the surface to be measured. The sensor is a small thermistor pearl of high thermalconductivity material (silver and gold) so that short response times and small heat capacity are achieved. Accuracy of the instrument is better than $0.1{ }^{\circ} \mathrm{C}$ with a full-scale response time of four seconds. Two readings were taken with the Ultrakust instrument at the condensation measurement sites described below. One reading was of the surrounding cave wall and the second reading of the "dummy" metal plate used to check that sensor surface temperatures were the same as rock-surface temperatures.

The condensation measurement sites were the Organ Loft, the Cathedral, the Banquet Chamber and the Blanket Chamber (Fig. 1). The Organ Loft is a cul-de-sac passage. Here there is little air exchange with the outside and conditions are stable. The Cathedral site is also within the deep cave zone, but in this case along the main airflow route. The Banquet Chamber is also on the main airflow route that is closer to the main passage towards the Upper Entrance. Four condensation sensors were installed at each measurement site on a vertical portion of the cave wall $900 \mathrm{~mm}$ above the floor and attached to four dedicated Campbell Scientific CR 10 data loggers. Measurements were taken over a 13-month period from December 1999 to December 2000.

\section{ASSESSMENT OF THE CONDENSATION MODEL}

The combined convective water vapour transfer coefficient, $\mathrm{k}_{\mathrm{v}}$, in equation (4) is a function of air movement and surface roughness (Pedro \& Gillespie, 1982; McAdams, 1954). Compared to the boundary layer outdoors, surface roughness is relatively constant in most caves. In an open environment where wind speed varies greatly and can reach much higher levels than in caves, wind is an important variable. In the case of the Glowworm Cave, however, rates of airflow are extremely low. With the exception of the area immediately inside the upper Entrance, maximum airflow rates though the cave never exceeded 0.08 $\mathrm{m} \mathrm{s}^{-1}$. When the cave door was open the airflow as measured at the Upper Entrance for the study period was on average $0.16 \mathrm{~m} \mathrm{~s}^{-1}$. When the door was closed airflow was nil or too slight to be measured even with a sensitive hot wire anemometer. For the above reasons, the effect of the $\mathrm{k}_{\mathrm{v}}$ term on $\mathrm{C}$ can be expected to be relatively steady. Moreover, the sensitivity of $\mathrm{C}$ to changes in airflow is small compared to the effect of changes in other variables shown in equation (6). De Freitas \& Schmekal (2003) confirm this and show empirically that $\mathrm{k}_{\mathrm{v}}=3.7 \mathrm{~g} \mathrm{~m}^{-2} \mathrm{~s}^{-1}$ in equation (1) fits well with observations of $\mathrm{C}$ regardless of the location within the cave and gives good results regardless of season. A summary of results are shown in Table 1 and Fig. 4.

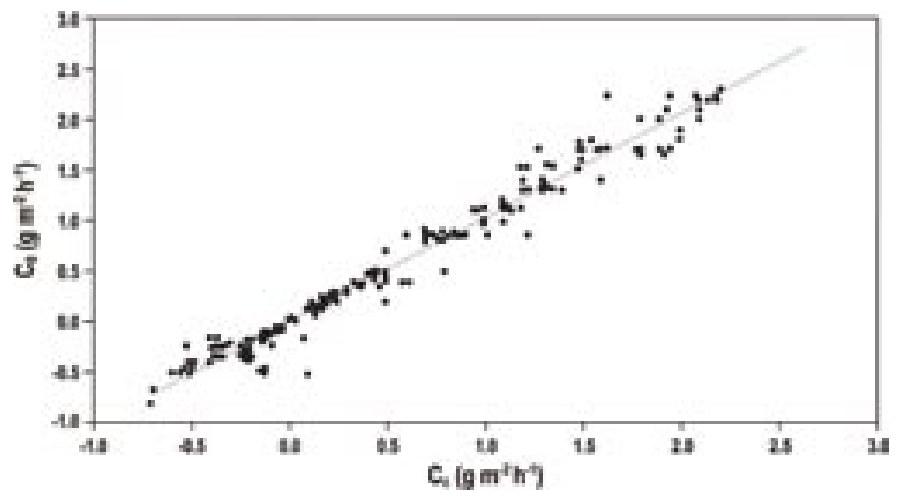

Fig. 4. A comparison of calculated and observed condensation rates, $\mathrm{C}_{\mathrm{c}}$ and $\mathrm{C}_{\mathrm{o}}$ respectively $\left(\mathrm{g} \mathrm{m}^{-2} \mathrm{~h}^{-1}\right)$. The standard deviation is $0.165 \mathrm{~g}$ $\mathrm{m}^{-2} \mathrm{~h}^{-1}$, the Pearson's product moment correlation coefficient $\left(\mathrm{r}^{2}\right)$ is 0.97 and the sample size is 750 . Note that over-plotting of data points occurs frequently because condensation rates change only very gradually over time.

\begin{tabular}{|c|c|c|c|c|}
\hline Location & Sample size & Mean & $\begin{array}{c}\text { Standard } \\
\text { deviation }\end{array}$ & $\mathbf{r}^{2}$ \\
\hline $\begin{array}{c}\text { Banquet } \\
\text { Chamber }\end{array}$ & 250 & 0.003 & 0.070 & 0.96 \\
\hline Cathedral & 250 & 0.078 & 0.292 & 0.96 \\
\hline Organ Loft & 250 & 0.110 & 0.039 & 0.99 \\
\hline Entire data set & 750 & 0.062 & 0.165 & 0.97 \\
\hline
\end{tabular}

Table 1. Statistical analysis showing the mean difference between $\mathrm{C}_{\mathrm{o}}$ and $\mathrm{C}_{\mathrm{c}}\left(\mathrm{g} \mathrm{m}^{-2} \mathrm{~h}^{-1}\right)$, the standard deviation $\left(\mathrm{g} \mathrm{m}^{-2} \mathrm{~h}^{-1}\right)$ and Pearson's product moment correlation coefficient $\left(\mathrm{r}^{2}\right)$ at three measurement sites in the cave.

\section{CLOSED-DOOR AND OPEN-DOOR EXPERIMENTS}

Since rock-surface temperature throughout the cave is relatively stable (Table 2), the temperature of the cave air is the main factor that influences net condensation rates. Cave air temperature is jointly determined by outside air temperature and cave ventilation rate, which is itself a function of outside air temperature. Annually, outside air temperature varies between $0.2^{\circ} \mathrm{C}$ and $28.1^{\circ} \mathrm{C}$. To assess the influence of outside conditions on condensation rates two experiments were conducted to determine what influence the exchange of cave air with outside air has on condensation rates. The closing and opening of the entrance-door can be used to control airflow through the cave and consequently cave air temperatures.

In the first experiment, the solid cave entrance-door remained closed for 85 hours, thereby minimising cave ventilation. The door was opened for two-to-three minutes about twice an hour during the business day (09:00 to $17: 30 \mathrm{~h})$ to give entry to visitor groups. In the second experiment, the solid door at the upper entrance was left open continuously for 87 consecutive hours, thus facilitating continuous air exchange with the outside. Conditions at the Banquet Chamber site 
(Figure 1) were typical of conditions through the cave, so the results for this site was shown as indicative of process operating. Conditions inside and outside the cave during these experiments are shown in Figures 5 and 7. The effects on condensation are shown in Figures 6 and 8. On both occasions airflow in both directions through the cave was recorded. In Figures 5 and 7 , a positive value indicates condensation $\left(\mathrm{C}_{(+\mathrm{ve})}\right)$ is occurring while a negative value indicates that evaporation of condensate $\left(\mathrm{C}_{(-\mathrm{ve})}\right)$ is taking place.

In the door-closed experiment (Fig. 5 and 6) airflow through the cave was kept to a minimum, despite a strong cave-to-outside thermal gradient (Fig. 5). The results show a small vapour flux hovering just above and just below zero (Fig. 6). A near equilibrium moisture balance was sustained over the entire period the door was closed, varying between $\mathrm{C}=10.3 \mathrm{~g} \mathrm{~m}^{-2}$ and $\mathrm{C}=-9.9 \mathrm{~g} \mathrm{~m}^{-2}$. In the door-open experiment (Fig. 7 and 8) evaporation rates in the cave are up to five times larger than on nights when the entrance-door was shut (Fig. 5 and 6). The largest evaporation rate was recorded on the third day of the door-open experiment at $07: 00 \mathrm{~h}$, when the temperature dropped to $14.8^{\circ} \mathrm{C}$ in the Banquet Camber and evaporation rate rose to $2.41 \mathrm{~g} \mathrm{~m}^{-2} \mathrm{~h}^{-1}$ (Fig. 8).

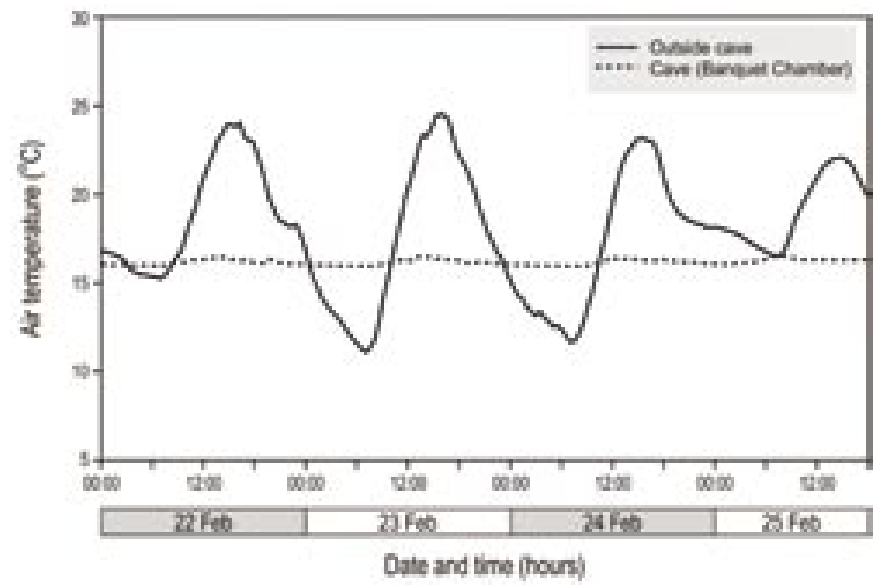

Fig. 5. Air temperature in the cave at the Banquet Chamber site and outside the cave during the closed-door experiment, 23-25 February 2000.

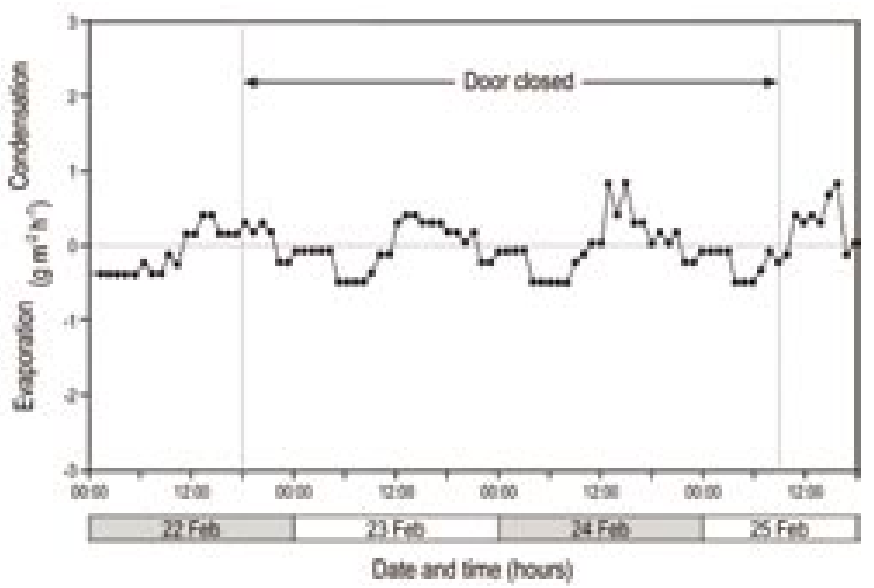

Fig. 6. Results of closed-door experiment for the Banquet Chamber site showing measured condensation and evaporation rates. The entrance door was closed from 18:00 h on 22 February 2000 to 09:00 h on 25 February 2000.

\section{CONCLUSIONS}

The work describes an explanatory model of processes leading to condensation using data based on measurements of condensation and evaporation as part of a single continuous process of water vapour flux. The results show that the model works well. However, one of the most important messages from the research reported here is the introduction of the condensation sensor. The results show that condensation in caves can actually be measured and monitored, virtually in real time. In conjunction with the recent developments in data logging equipment, this opens exciting perspectives in cave climate studies, and, more generally, in hydrogeological studies in karst terrains.

The results are also relevant to aspects of tourist cave management. Ideally, there would be no need to induce either condensation or evaporation in a cave. Intuitively, one would think that the best course would be to keep the system at equilibrium to avoid both drying-out and excessive moisturizing, both of which could be detrimental to the cave formations. However, the results show that for show caves where care and proper management is a concern, condensation/ evaporation can be predicted or controlled by

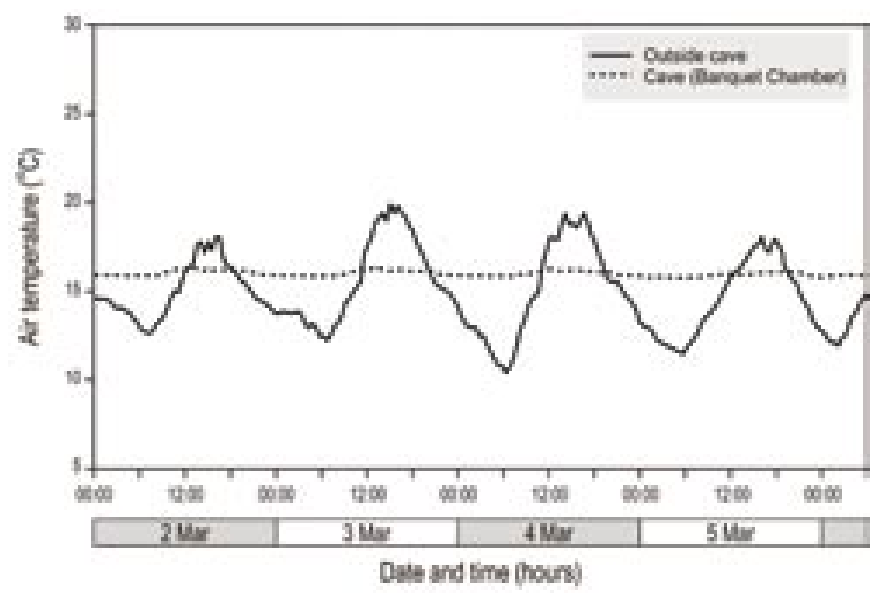

Fig. 7. Air temperature in the cave at the Banquet Chamber site and outside the cave during the open-door experiment, 2-5 March 2000.

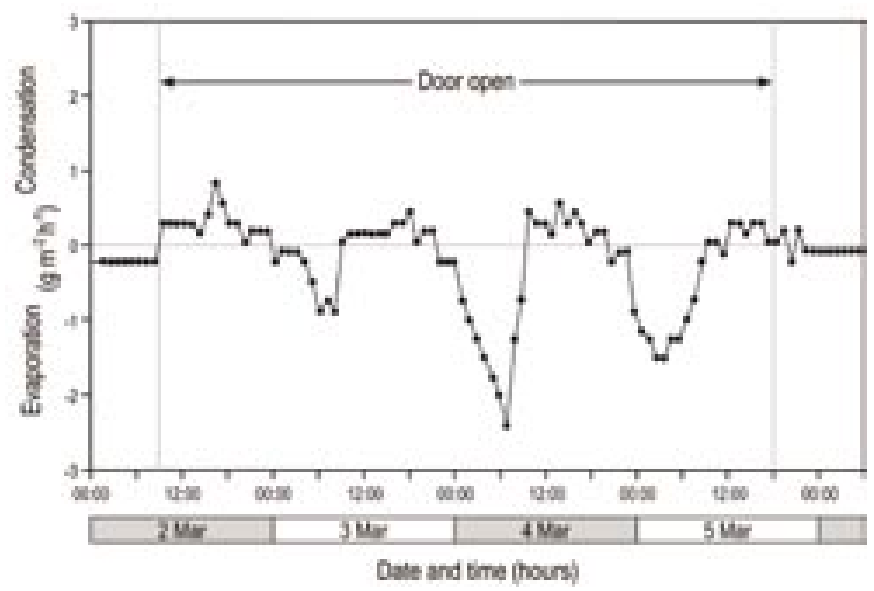

Figure 8. Results of the open-door experiment for the Banquet Chamber site showing measured condensation and evaporation rates. The entrance door was kept open from 09:00 h on 2 March 2000 to $18: 00$ h on 5 March 2000. 


\begin{tabular}{|c|c|c|c|c|}
\hline & Maximum & Minimum & Mean & Range \\
\hline Blanket Chamber & 15.3 & 13.3 & 14.7 & 1.3 \\
\hline Banquet Chamber & 15.3 & 14.0 & 14.7 & 1.4 \\
\hline Cathedral & 15.4 & 14.0 & 14.1 & 0.5 \\
\hline Organ Loft & 14.3 & 13.8 & 14.5 & 1.3 \\
\hline Mean for cave & 15.1 & 13.8 & & \\
\hline
\end{tabular}

Table 2. Rock-surface temperature $\left({ }^{\circ} \mathrm{C}\right)$ at the four condensation measurement sites over the study period. Values are given for maximum, minimum and mean temperature as well as the temperature range for each site and mean for cave.

controlling ventilation. Because cave rock-surface temperatures do not vary much, condensation is essentially a function of cave air temperature and the processes that affect it, mainly, air exchange with outside.

Although the results provide insight into the environmental effects of managementinduced changes, there is need for more work on caves in other climate regimes. Future research should also aim to develop an understanding of the role of condensation in the water and energy balance of caves. Other work might focus on spatial variation of condensation through large caves and factors that affect the geochemical composition of condensate.

\section{ACKNOWLEDGEMENTS}

This work was funded in part by New Zealand Department of Conservation Research Grant 3272.

\section{REFERENCES}

Cigna A. \& Forti P., 1986 - The speleogenetic role of air flow caused by convection. International Journal of Speleology, 15: 41-52.

Davis D. R. \& Hughes J.E., 1970 - A new approach to recording the wetting parameter by the use of electrical resistance sensors. Plant Disease Reporter, 54: 474479.

De Freitas C.R., 1998 - Cave monitoring and management: The Glowworm Cave, New Zealand. In: Cave and Karst Management in Australasia XII. Proceedings of the Twelfth Australasian Conference on Cave and Karst Management, Waitomo, Australasian Cave and Karst Management Association, Carlton South, Victoria: 5566.

De Freitas C.R. \& Banbury K., 1999 - Build up and diffusion of carbon dioxide in cave air in relation to visitor numbers at the Glowworm Cave, New Zealand. In: Cave Management in Australasia XIII. Proceedings of the Thirteenth Australasian Conference on Cave and Karst Management, Mount Gambier, South Australia. Australasian Cave and Karst Management Association, Carlton South, Victoria: 84-89.

De Freitas C.R. \& Littlejohn R.N., 1987 - Cave climate: assessment of heatand moisture exchange. International Journal of Climatology, 7: 553-569.

De Freitas C.R., Littlejohn R.N., Clarkson T.S., Kristament I.S., 1982 - Cave climate: assessment of airflow and ventilation. International Journal of Climatology, 2: 383-397.
De Freitas C.R. \& Schmekal A.A., 2003 - Condensation as a microclimate process: Measurement, numerical simulation and prediction in the Glowworm tourist cave, New Zealand. International Journal of Climatology, 23 (5): 557-575.

Dreybrodt W., Gabrovsek F. \& Perne M., 2005 Condensation corrosion: a theoretical approach. Acta Carsologica, 34 (2): 317-348.

Dublyansky V.N. \& Dublyansky Y.V., 1998 - The problem of condensation in karst studies. Journal of Cave and Karst Studies, 60 (1): 3-17.

Dublyansky V.N. \& Dublyansky Y.V., 2000 - The role of condensation in karst hydrogeology and speleogenesis. In: Klimchouk A., Ford D.C., Palmer A.N. \& Dreybrodt W. (Eds). Speleogenesis, Evolution of Karst Aquifers. National Speleological Society, Huntsville: 100-111.

Gillespie T.J. \& Kid G.E., 1978 - Sensing duration of leaf moisture retention using electrical impedance grids. Canadian Journal of Plant Science, 58: 179-187.

Giovanni B., 2004 - Clouds in caves. Speleogenesis and Evolution of Karst Aquifers, 2 (2), 8 p.

Häkell H., 1980 - New developments of an electrical method for direct measurement of the wetness-duration on plants. Agricultural Meteorology, 22: 113-119.

McAdams W.H., 1954 - Heat transmission (third edition). McGraw-Hill, New York.

Jensen D., 1983 - Computer simulation of an aerological diagram. Meteorology Australia, 3 (2): 13-16.

Monteith J.L., 1957 - Dew. Quarterly Journal of the Royal Meteorological Society, 83: 322-341.

Neiburger M., Edinger J.G. \& Bonner W.D., 1982 Understanding Our Atmospheric Environment (second edition). W.H. Freeman and Company, San Francisco.

Pedro M.J. \& Gillespie T.J., 1982 - Estimating dew duration. I. Utilizing micrometeorological data. Agriculture Meteorology, 25: 283-296.

Richards K., 2002 - A review of scaling theory for hardware models and application to an urban dew model. Physical Geography, 23 (3): 212-232.

Richards K. \& Oke T. R., 2002 - Validation and results of a scale model of dew deposition in urban environments. International Journal of Climatology, 22: 1915-1933.

Rosenberg N.J., 1969 - Evaporation and condensation on bare soil under irrigation in the central Great Plains. Agronomy Journal, 61: 557-561.

Tarhule-Lips R.F.A. \& Ford D.C., 1998 - Condensation corrosion in caves on Cayman Brac and Isla de Mona. Journal of Cave and Karst Studies, 60 (2): 84-95. 